\section{We are divided by imaginaries lines. La fotografía y los mapas en Bering. Equilibrio y resistencia, de Lourdes Grobet}

We are divided by imaginaries lines.

Photography and maps in Bering. Balance and resistance,

by Lourdes Grobet

\section{Eréndira Derbez Campos erendiraderbez@gmail.com}

Universidad Iberoamericana, México.

FECHA DE RECEPCIÓN marzo 25, 2019

FECHA DE APROBACIÓN septiembre 30, 2019

FECHA dE PUBLICACIÓN enero 1,2020

https://doi.org/10.32870/ elojoquepiensa.v0i20.320

\section{Resumen / Bering. Equilibrio y} resistencia es el nombre de una exhibición y también de un documental creado por la artista mexicana Lourdes Grobet. En el siguiente artículo me centraré en el trabajo de cine documental de esta reconocida fotógrafa. Grobet, interesada en la separación política entre la Diómada Mayor (Rusia) y la Diómada Menor (EE.UU.) en el estrecho de Bering, se pregunta por la frontera entre Estados Unidos y Rusia. Las fronteras son un espacio de control y de poder, pero ¿quién decide dónde comienzan las fronteras? ¿Qué implicaciones sociales tienen? Grobet trabaja con migraciones y las comunidades nanook. Se centra en la vida cotidiana, las tradiciones antiguas y el balance entre la vida moderna estadounidense y sus raíces.

Palabras Clave / Lourdes Grobet, Bering, cine documental, fronteras, cartografía, fotografía.
A B STR ACT / Bering. Balance and Resistance is the name of both an exhibition and a documentary film created by the Mexican artist Lourdes Grobet. In the following article I will focus on the documentary film work of this renowned photographer. Grobet, interested in the political separation between the Big Diomede Island (Russia) and the Little Diomede Island (USA) in the Bering Strait, wonders about the border between the United States and Russia. Borders are a space of control and power, but, who decides where borders begin? What social implications do borders have? Grobet works with migrations and Nanook communities. She focuses on everyday life, ancient traditions and the balance between modern American life and the Nanook roots.

Keyw ORD S / Lourdes Grobet, Bering, documentary film, borders, cartography, photography. 


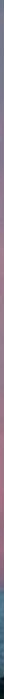

Bering. Equilibrio y resistencia

(Lourdes Grobet, 2013).

\section{INTRODUCCIÓN}

The photographer both loots and preserves, denounces and consecrates. Susan Sontag, On Photography

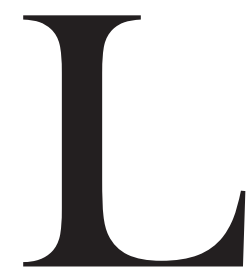

ourdes Grobet trabaja en varias de sus obras fotográficas, así como en su primer largometraje documental, las implicaciones sociales de las fronteras. Para Bering. Equilibrio y resistencia (2013), Grobet se traslada a la región de Beringia, por donde, en teoría, cruzaron los primeros seres humanos que poblaron el continente americano. Grobet trata la problemática entre Rusia y Estados Unidos en la zona, que ocasionó la división de familias completas.

El trabajo de Grobet, crítico con la construcción de las fronteras, es uno que, paradójicamente, al contar las historias de los pobladores desde la fotografía, conlleva un acto de poder: quien fotografía -al igual que quien mapea- al aprehender a los otros, ejerce poder sobre los representados, los capturados. Con ello hay una tensión constante entre la dialéctica de quien representa -conquistador, el poderoso- y el representado -quien es conquistado, capturado, aprehendido.

A lo largo del siguiente texto estudio cómo en Bering. Equilibrio y resistencia se retratan las implicaciones políticas y sociales de las fronteras y la cartografía. Presento un análisis del documental tras la atenta escucha de los diálogos durante la película, 
y hago una revisión del método de trabajo de la artista. Para ello indago en su metodología de trabajo de campo a través de entrevistas con Grobet y el análisis de otros de sus proyectos; de forma paralela sigo una ruta de lecturas que se convertirán en reflexiones respecto a la obra de la artista.

En este análisis del largometraje documental los referentes conceptuales son las implicaciones de la fotografía y la cartografía, la discusión respecto a la conformación de los Estados, la relación de los mapas, la otredad y el arraigo. Para ello parto de la obra teórica alrededor de la fotografía de la filósofa Susan Sontag (2013), y sobre la construcción de los Estados coloniales retomo el trabajo de la antropóloga feminista Rita Segato (2007) y del politólogo e historiador Benedict Anderson (1993). De este último considero sus nociones sobre la cartografía junto con lo escrito por la historiadora del arte María Luisa Durán y Casahonda Torack (2014, 2016). Sobre la noción de territorio, vigilancia y otredad me enfoco en el trabajo del colectivo Raqs Media (2009), y de Mireille Rosello, de la Amsterdam School for Cultural Analysis, y Stephen Wolfe (2017), profesor de literatura inglesa que se ha destacado en la investigación sobre fronteras y los territorios fronterizos.

Lourdes Grobet (Ciudad de México, 1940- ) es una artista mexicana reconocida por su trabajo fotográfico. Es célebre por sus series sobre lucha libre mexicana y por haber pertenecido a Proceso Pentágono, un grupo de artistas activo durante la década de los 70 y 80 en México, con un carácter contestatario ante las políticas represivas del Estado. Inicialmente formaron parte del colectivo Felipe Ehrenberg, Carlos Fink, José Antonio Hernández Amezcua y Víctor Muñoz, y posteriormente se unieron Carlos Aguirre, Miguel Ehrenberg, Rowena Morales y la misma Grobet. El siguiente texto trata de Bering. Equilibrio y resistencia, el primer largometraje de Lourdes Grobet, que se estrenó en 2013. Este proyecto comenzó a inicios del año 2000 cuando la artista se interesó en las islas Diómada Mayor y Diómada Menor en el estrecho de Bering, que se encuentran en la frontera entre Estados Unidos y Rusia. Es a partir de esta inquietud que nace el proyecto de Equilibrio y resistencia, que también es el nombre de una exposición compuesta de fotografías y videoinstalaciones que se ha exhibido en el Museo Archivo de la Fotografía y en el Centro de Cultura Digital, en Ciudad de México, así como en el Museo del Hombre en París. Tanto la exposición como el documental son parte del mismo proceso de investigación creativa.

A casi cien años después del considerado primer trabajo de cine documental, Nanuk, el esquimal (Nanook of the North, Robert J. Flaherty, 1922), Lourdes Grobet vuelve a llevar cámaras de video al Polo Norte. En su largometraje, la artista y realizadora inquieta al espectador con una historia profundamente local de la región de Beringia que roza temas universales: la frontera, la migración, el desplazamiento, la familia, las tradiciones, la religión y la supervivencia.

\section{Alaska, entre el Viejo imperio RUSO Y EL NUEVO IMPERIO YANQUI. LOS LINAJES VENDIDOS}

La frontera entre Alaska y Rusia es de donde parte la búsqueda de Grobet para reflexionar sobre quién decide dónde se establece una línea fronteriza. La artista trabaja con migraciones y las comunidades Nanook en el norte del continente americano. A lo largo de su documental se centra en su vida cotidiana, en las tradiciones y en el balance entre la vida moderna estadounidense con el consumo de estupefacientes, el comercio por internet, la extracción del petróleo y la crisis climática en contraposición con sus costumbres ancestrales, la caza, las danzas, la música y la lengua inuit. La frontera es esa "línea imaginaria" -así es como la llama un personaje en el documental-que tuvo efectos contundentes ya que separó a familias Nanook en la repartición territorial del siglo XIX entre Rusia y Estados Unidos.

Cada frontera es el resultado de un proceso social o de uno geológico -como las cordilleras y los ríos-. En el caso de las primeras, las creadas por el ser humano, la artista trabaja 
FIGURA 1. Treasury Warrant in the Amount of \$7.2 Million for the Purchase of Alaska. 1868. Catálogo del Archivo Nacional de Estados Unidos.

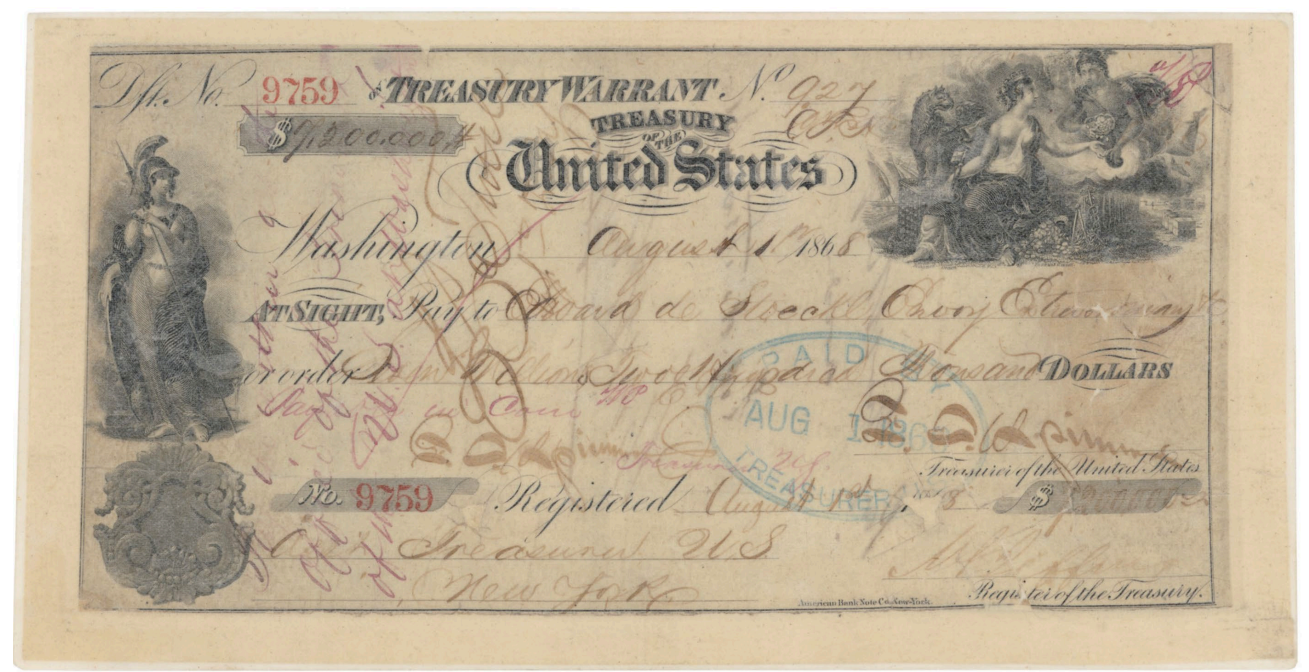

con una fisura emblemática: alguien se colocó en la posición de autoridad facultada para dividir el estrecho de Bering. El puente de Beringia, que abarcó a Siberia (Asia), al oeste de Alaska (América) y al mar de Bering, es donde se estima fue el lugar por donde el ser humano migró hacia el continente americano durante una glaciación: de este modo los amerindios descienden de andariegos siberianos. Ese espacio emblemático en la historia de la migración humana actualmente es inaccesible. Hoy cruzar este brazo de mar entre Asia y América en lancha implica poner en riesgo la vida, no por las inclemencias del mar sino por las de los humanos. Los pobladores estadounidenses no pueden cruzar al territorio ruso porque pueden ser víctimas de disparos desde la base militar rusa.

Entre Alaska y Siberia hay dos islas: la Diómedes Menor y la Diómedes Mayor. Sus habitantes estuvieron hace dos siglos hermanados al ser familiares que fueron separados por una línea que se trazó sobre el mar cuando el Imperio Ruso vendió el territorio de Alaska en 1868 [Figura 1]. De este modo, la primera isla pertenece a Estados Unidos y la segunda a Rusia. Ambas potencias que, además, tras el fin de la segunda guerra mundial, se enfrentaron durante la guerra fría, un conflicto cuyo fin se tiende a situar a mediados y finales de la década de los 80 con los primeros años de la Perestroika y la caída de otra frontera: el muro de Berlín. El trabajo de investigación de Grobet sobre la región de Beringia comenzó alrededor de tres décadas después del fin del enfrentamiento [FIGURA 2].
Únicamente tres kilómetros separan a las dos islas. Pese a ello es imposible cruzar de un lado a otro, pues hay una pesada línea imaginaria entre ellas. Al existir una base militar en la Diómedes Mayor los habitantes de la Diómedes Menor se consideran vigilados. Quienes vivieron antes de la instalación de la base fueron obligados a desplazarse a Naukan, en Rusia. Nunca más se volvieron a unir las familias, un destino que remite a quienes, fracturados por el muro de Berlín, no pudieron reencontrarse tras la separación entre Alemania Occidental y la Alemania Oriental [FIGURA 3].

\section{APREHENDER EN LOS MAPAS}

La división entre imperios y el reparto geográfico se materializan en los mapas. Existe una serie de ideologías contenidas en este: es la representación gráfica de un espacio que se conquista, es un objeto que registra territorios que fueron seleccionados y diseccionados al ser cortados por fronteras. Es por ello que son un instrumento necesario para el Estado colonial. Sirven para señalar lo que -y a quienes- se conquista, lo que se tiene derecho a extraer, lo que se despoja y depreda. De este modo los mapas son discursos de poder: en ellos anotamos los nombres que los humanos le hemos otorgado a los lugares, trazamos líneas que se vuelven límites que nos separan y, en su caso, nos enjaulan. Los mapas se estudian desde la educación primaria, se leen, se memorizan, se compran, se marcan con alfileres, se descargan 
FIGURA 2. Imagen satelital del estrecho

de Bering: Alaska (derecha), Islas

Diómedes (centro) y Rusia (izquierda).

Fotografía: NASA/GSFC/JPL/MISR.

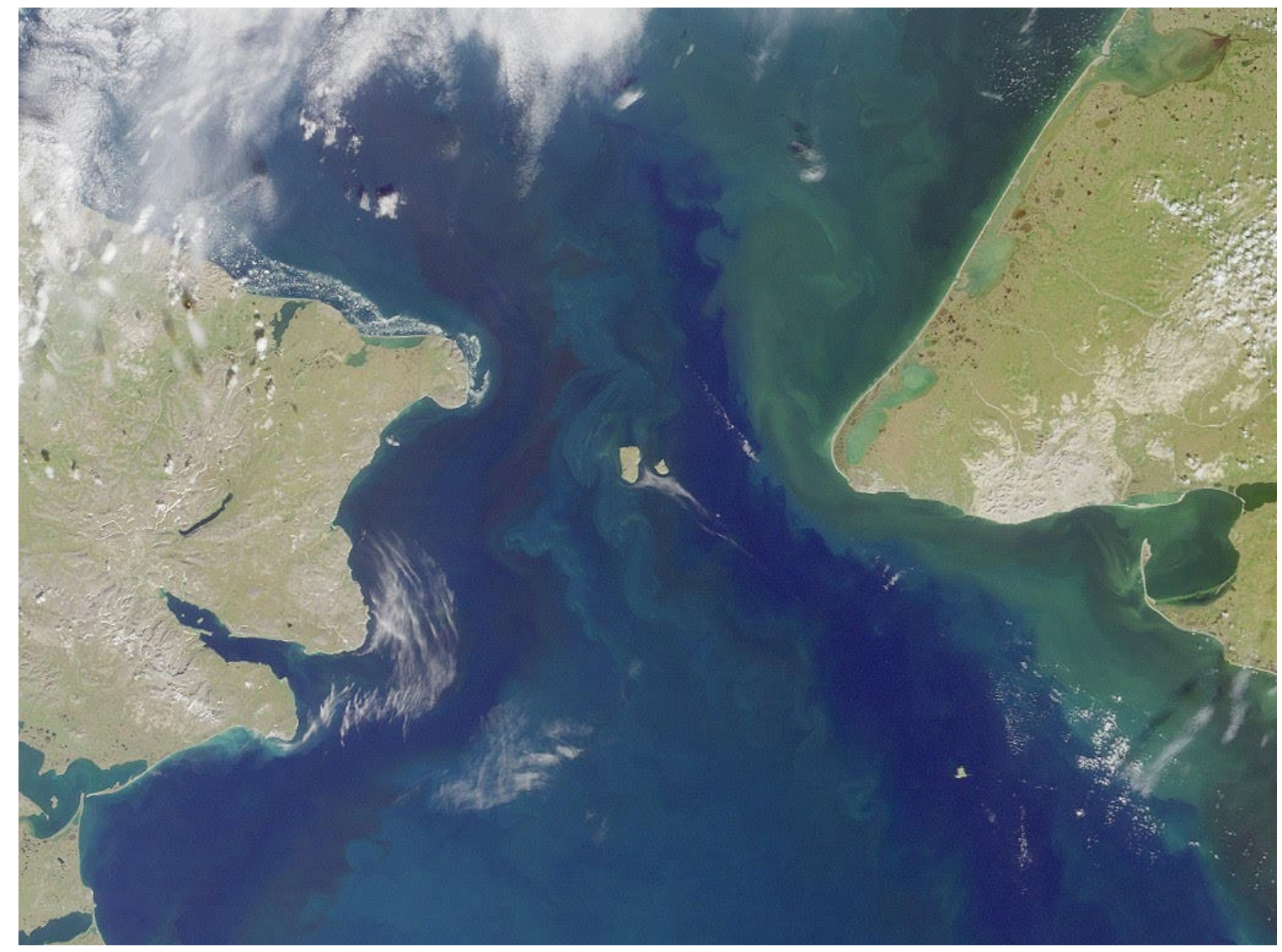


de internet, se programan en códigos computacionales, se coleccionan, se estudian, se discuten y se disputan.

Durante el siglo XIX los mapas cobraron un papel imprescindible en los proyectos coloniales europeos -encabezados por Estados como Bélgica, Francia, Reino Unido, España, Portugal, Rusia, Países Bajos y Dinamarca-. Posteriormente, tras alcanzar su independencia, los Estados Unidos de América desarrollaron su propio sistema de colonias en Latinoamérica. Estos fueron una herramienta indispensable para entender la modernidad y de este modo surgieron con ello profesiones específicas alrededor. Tal como explica el historiador y politólogo Benedict Anderson (1993), guiado por su “mapa imaginado”, el Estado colonial “organizó las nuevas burocracias educativas, jurídicas, de salubridad, de policía y de inmigración que ya estaban formando sobre el principio de unas jerarquías etnoraciales que, sin embargo, siempre fueron interpretadas como series paralelas" (p. 236). Fue gracias a los mapas que el Estado colonial imaginó su poder: "la naturaleza de los seres humanos que gobernaba, la geografía de sus dominios y la legitimidad de su linaje” (p. 229). De esta forma, Anderson concibe al mapa, al censo y al museo como elementos que moldearon profundamente al Estado colonial. Sobre la cartografía, Anderson (1993) apunta que desde la invención del cronómetro por John Harrison en 1761 se "hizo posible el cálculo preciso de longitudes, toda la superficie curva del planeta había estado sometida a una red geométrica que cuadriculaba mares vacíos y regiones inexploradas, en recuadros medidos. La tarea, por decirlo así, de 'llenar' estos recuadros, sería realizada por exploradores, agrimensores y fuerzas militares" (p. 242). De este modo, con los avances tecnológicos y científicos, el mapa en la modernidad cobra distintos sentidos: servirá para marcar a los conquistados, a los seres racializados. El surgimiento de la noción de la raza para dividir a los seres humanos de acuerdo a sus características fenotípicas se entiende perfectamente en el contexto del Estado colonial: los conquistadores biologizaron a los oprimidos, los nombraron y teorizaron con respecto a ellos, los caracterizaron como inferiores para así adueñarse de los recursos de sus territorios, como en Alaska. En el caso de los esclavistas, para poder adueñarse de sus cuerpos. Los linajes, las tradiciones y las identidades fueron confiscadas para encajar en los trazos cartográficos. Cuestionar la cartografía es una forma de cuestionar al Estado colonial; cuestionar las "líneas imaginarias" lleva a preguntarse por aquello que Anderson llama comunidades imaginadas. Un país se forma por una comunidad que, al ser un constructo social, ha sido imaginada por personas que se perciben como parte de un grupo distinto a otro que se encuentra del lado opuesto de la línea.

Sobre la arbitrariedad de quién decide dónde comienza un mapa, la artista Lourdes Grobet lleva varias décadas formulando preguntas desde su obra. Ejemplo de ello es Engrapando la frontera (1990) con el Taller de Arte Fronterizo -Border Artistic Workshop-, Cubanos fuera de Cuba (1994) o su serie de dípticos Bering este-oeste (2008). En el documental, esta arbitrariedad es una pregunta constante: "Nos vendieron (...) No creo que haya sido correcto que América nos comprara, ellos tuvieron una guerra antes y dijeron que no se podía comprar personas y es básicamente lo mismo. Compraron una raza completa, no nos hicieron esclavos pero nos compraron, compraron nuestras tierras", dice un personaje frente a la cámara. Tiene razón: sus antepasados fueron vendidos, con todo y territorio $-\dot{\mathrm{C}}^{\mathrm{O}}$ el territorio fue vendido con todo y las personas?- por el Imperio Ruso a los Estados Unidos de América, the land of the free. La frase del hombre es un enunciado contundente para ejemplificar la arbitrariedad de las fronteras y con ello lo violento que pueden resultar los mapas, al representar la violencia colonial que guarda la cartografía.

La división de mediados del siglo XIX es contemporánea porque sus efectos continúan, son un tema presente en la comunidad que retrata Grobet. Tiene un peso simbólico: hay una carga distinta entre ser los de este lado de Bering y no de ese otro lado. En este siglo XXI, tras el conflicto soviético estadounidense del siglo XX, el pertenecer a un lado conlleva otro tipo de pugna en el imaginario de los habitantes, y también 


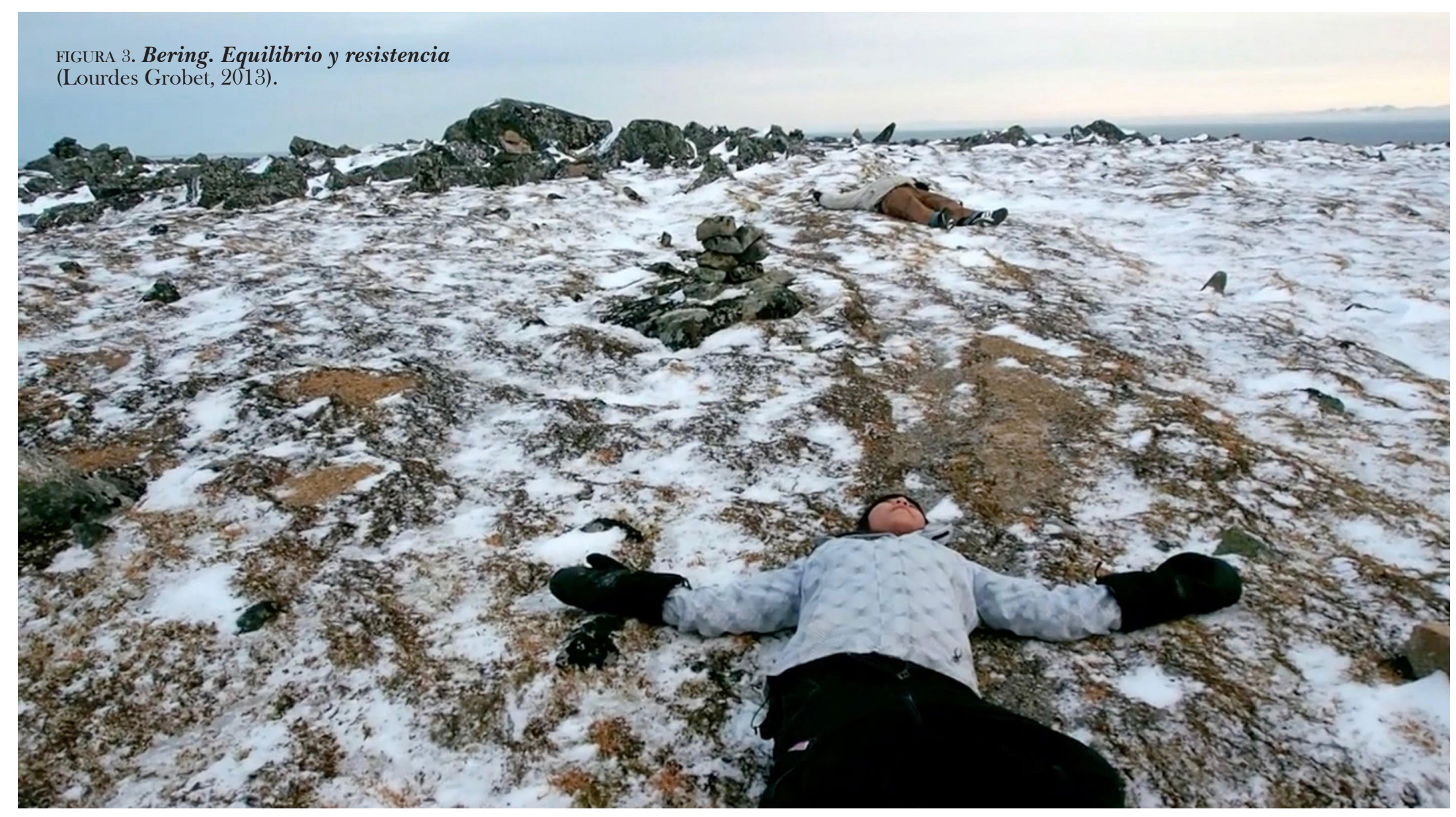

en el de quienes observamos la obra de Grobet. Hay un lado que se anuncia como "libre" y "seguro", que se promueve como "democrático", y otro que es lejano y desconocido. Las ideas sobre ambos lados han llegado a nosotros a través de la propaganda del cine comercial y de la prensa. Nuestro imaginario sobre Rusia y Estados Unidos está configurado con ficciones fílmicas de Hollywood. Películas de espías y de superhéroes que tienen consecuencias en otras geografías, tal como lo mencionan los investigadores Mireille Rosello y Stephen Wolfe (2017) cuando hablan de la frontera entre Rusia y Finlandia. Para ellos el significado de las fronteras va mucho más allá de lo visual o incluso de los cinco sentidos básicos cuando se organizan los límites entre lo "seguro" y las áreas "peligrosas" (pp. 1-2).

Los procesos de conquista y racialización de siglos atrás tienen, como se mira y se escucha en el documental de Grobet, consecuencias palpables en este siglo XXI. En el continente americano persiste una historia de dominación colonial. Así, en palabras de la antropóloga argentina Laura Rita Segato: "Se hace posible la percepción naturalizada del sufrimiento y la muerte de los no blancos, algo que se presenta casi como una costumbre en las sociedades del Nuevo Mundo” (2017, p. 144). El Estado actual, de acuerdo con Segato, es heredero jurídico y patrimonial de los Estados metropolitanos que instauraron la colonia mediante la conquista y sentaron las bases para que sus sucesores, los Estados nacionales controlados por elites criollas blancas o blanqueadas, como el caso de Estados Unidos, continuaran garantizando el proceso de expropiación de las posesiones y del trabajo de los pueblos no blancos. Pueblos como los inuit.

\section{LOS CUERPOS CORTADOS}

Los territorios son cuerpos con cicatrices, manchas, excavaciones y cortes. El colectivo artístico Raqus, fundado en 1992, describe bien a ese cuerpo en el libro Emotional Cartography. "Como si el cuerpo fuera un territorio, su mapeo es el primer 
paso en su gobernanza, y la subyugación de sus límites a la regulación y el control" (p. 16). Este cuerpo regulado, gobernado, ha sido también a lo largo del tiempo uno vulnerado. Desde el poder político o militar se decide el destino de decenas, cientos o miles de habitantes racializados. "Las imágenes que representan a seres humanos, así como lo hacen las de los mapas, ubican similitudes y diferencias, cercanías y lejanías, lo familiar y lo extraño” (p. 17). Se traza la frontera entre nosotros y ellos -los otros-. "Estas categorías, que se basan en el sentido de lo que concebimos como similar o diferente a lo que somos, o en el lugar en el que estamos parados, nuestro sentido de orientación” (La traducción es mía).

Surgen así preguntas: quiénes son ellos, esos "otros", en dónde comienza el arraigo y dónde termina, qué personas valen lo "suficiente" como para ser consultadas y quiénes valen tan poco como para ser vendidos como accesorios de un territorio. Los otros son también parientes, familiares no tan lejanos: pero ahora los de allá hablan ruso y los de este lado hablan inglés. Durante el documental un personaje reflexiona sobre la lengua perdida y la relación con su identidad: "Puede que aún nos veamos como esquimales, probablemente nos veremos como esquimales por los próximos años. Pero nuestra lengua nativa será el inglés y lo mismo en el otro lado, su lengua probablemente ya es el ruso".

"No son malos", reflexiona otro personaje ante la cámara. "Me preguntaba, cuando crecía, por el enemigo”. Pero considera que el enemigo no son los rusos: "Si tenemos familiares ahí”. También tienen otro horario. Las islas, con sus escasos kilómetros de diferencia, pertenecen a husos horarios distintos: We say we're going to tomorrow and come back today. En Alaska es miércoles y en Rusia es jueves, explica el personaje mientras sonríe ante la cámara.

\section{Aprehender en LAS FOTOGRAFÍAS}

Susan Sontag en su emblemática serie de ensayos Sobre la fotografía [1975], señala que el acto de fotografiar es el de apropiarse de lo fotografiado. "Significa establecer con el mundo una relación determinada que parece conocimiento, y, por lo tanto, poder" (2013, p. 14). Grobet, como directora y fotógrafa, también se apropia al representar al otro. Lo hace desde una postura de respeto que, por la cercanía que consigue con los habitantes de Alaska, pareciera ser una de escucha: antes de cualquier acto fotográfico, el primer intercambio con la comunidad es verbal. Sin embargo, la cámara está ahí y quien fotografía al narrar la realidad, la deforma. El cine documental, aunque pretenda ser "fiel a la realidad" hace lo mismo: el elegir un encuadre, el incluir y excluir objetos de la toma, la apertura del diafragma y la distancia focal deforman lo visible. Los fotógrafos "deciden la apariencia de una imagen cuando prefieren una exposición a otra, los fotógrafos siempre imponen pautas a sus modelos. Aunque en un sentido la cámara en efecto captura la realidad, y no solo la interpreta, las fotografías son una interpretación del mundo tanto como las pinturas y los dibujos” (pp. 16-17). De la misma forma, las fotografías familiares de los personajes del documental tienen un papel protagónico entre los objetos de la intimidad de los hogares y las imágenes retratadas en las fotografías personales son un punto de partida en las historias [FIGURA 4].

\section{LAS FRONTERAS DESDE MÉXICO}

Grobet es una artista que desde los inicios de su carrera mantuvo posicionamientos políticos públicos, tal como lo hizo con Proceso Pentágono. El que hoy su trabajo toque temas como la migración y la frontera es porque forma parte de una discusión vigente, de un debate político encendido. Hablar de migración es hablar de algo que en México nos atañe y que cruza temas como género, racismo, desplazamiento, trata de personas, derecho, economía o arte: es parte del día a día, de las noticias llenas de declaraciones de políticos estadounidenses -y también mexicanos- que nombran como criminales a los migrantes. En Estados Unidos a veces solo dicen "mexicanos" para referirse a un inmigrante latinoamericano, con ello ignorando cualquier especifici- 


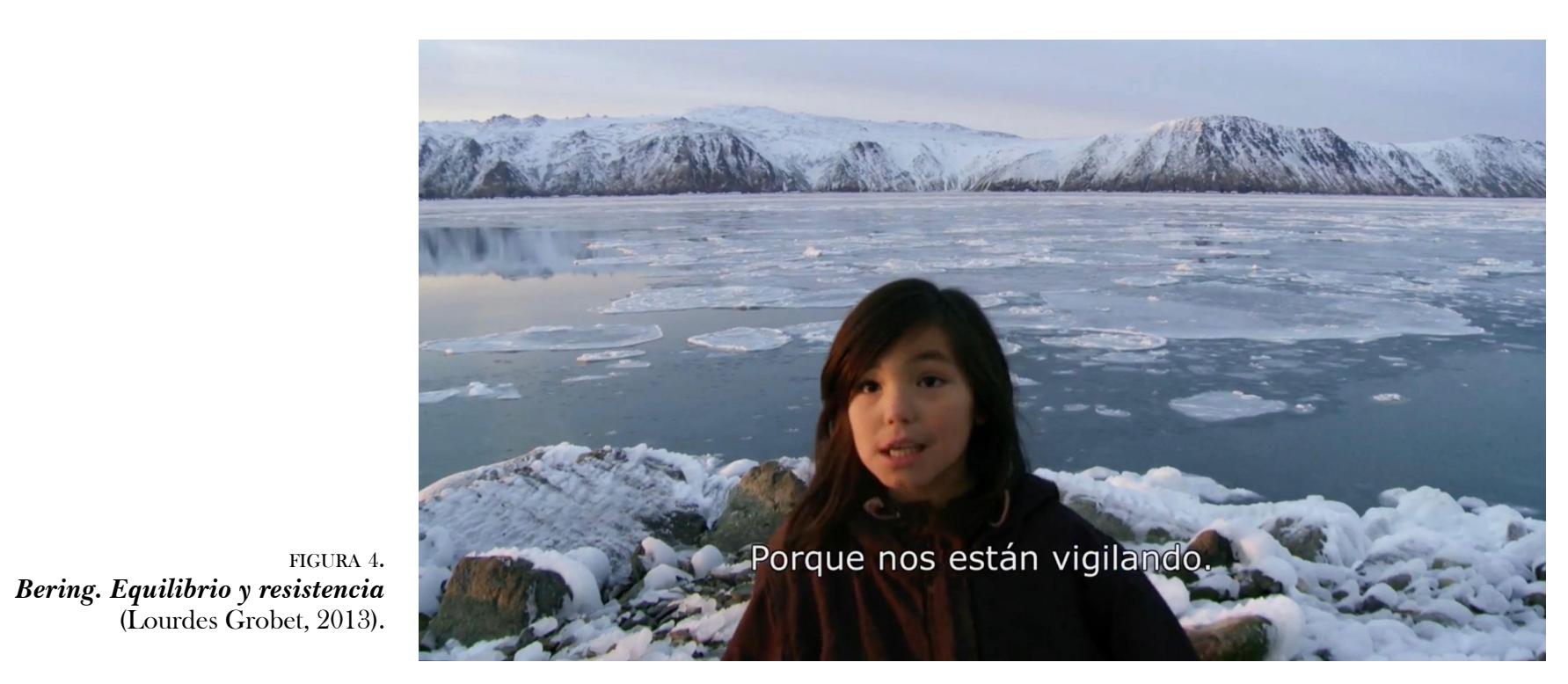

dad. En México sucede lo mismo cuando se refieren a los "centroamericanos". Donald Trump, por ejemplo, durante su campaña presidencial se refirió a los mexicanos como quienes traen drogas y crimen, que son violadores y que solo algunos son buenas personas. Los procesos migratorios han definido la realidad de México y también la de la población de origen mexicano que no habita nuestras tierras. Esto permea en el mundo artístico, ejemplo de ello son las expresiones plásticas y musicales de artistas chicanos. No se puede concebir al México del siglo XX e inicios del siglo XXI sin pensar en la migración. Tan solo en el aspecto económico las remesas son una parte fundamental del ingreso de muchas familias mexicanas; en los últimos meses de 2017 y enero de 2018 las remesas mensuales fueron superiores a los 2 mil 200 millones de dólares (Banco de México, 2018).

También la migración tiene una cara que no aparece a profundidad en los medios de comunicación: la tortura sexual, la extorsión y la trata que viven los migrantes que buscan cruzar por México. Artistas como Olivia Vivanco, con su serie fotográfica Reliquias (2013) han ahondado en el tema. También está el trabajo de Ana Teresa Fernández (1980) en su intervención Borrando la frontera (2015), entre otras artistas mexicanas que se concentran en temas migratorios. Podría suponerse que Lourdes Grobet, al ser nacida en México, se relacione con la migración y lo haga interesada en lo que sucede entre el Río Suchiate y el Río Bravo, pero su caso es distinto. No es el contexto de México lo que le atañe en
Bering. Equilibrio y resistencia. Sería absurdo y contradictorio pretender que como artista nacional debiera dedicarse únicamente a lo que sucede en su país de origen, como si de un berrinche patriotero se tratara: sus ideas también se mueven, se colocan en distintas partes del mundo. Como explica en una entrevista que me otorgó en marzo de 2018: "Uno de los temas de mi proyecto es hacer un análisis de lo que son las fronteras actualmente". Grobet, quien, por cierto, también es hija de un migrante suizo que llegó a México y se casó con una mexicana, opina: "La emigración está casi tan fuerte como en la prehistoria, la gente emigra hasta de forma sedentaria frente a la computadora". ¿Migramos con la mente? "La electrónica dio un cambio radical al concepto de frontera y movimientos, aunque no elimina las fronteras políticas”, responde.

Sobre cómo surgió la idea de trabajar con el estrecho de Bering, la artista explica que en el año 2000 realizaba una serie de fotografías sobre personas con discapacidad. Para ese trabajo fue a las instalaciones de El Colegio de México y ahí conoció a la académica Yolanda Muñoz, una investigadora que utiliza una silla de ruedas para desplazarse. Ella le dijo, según recuerda: "Lourdes, anoche soñé que me ayudabas a cruzar el estrecho de Bering”, y desde entonces no se pudo quitar la idea de la cabeza. Comenzó a investigar sobre el tema y desarrolló el proyecto de la mano de Muñoz.

Además del documental, la artista ha echado mano de distintos medios. La pieza The Bottle (2007) es un buen ejemplo de ello. Un objeto de plástico es lanzado a la deriva. Dentro 
de él va un rastreador de GPS (Global Positioning System) que permitió identificar, en tiempo real -bastaba entrar a la página web-, en qué parte del mundo se encontraba la boya. $\mathrm{Al}$ mismo tiempo el echarla al mar fue un acto performático en el que se leyó un manifiesto: "La boya que ahora lanzamos al mar es la mensajera de una verdadera conciencia”, dice Grobet, porque "la boya es la libertad sin raíces (...) La boya es ese mensajero del alma de los viajeros que saben que las fronteras del espíritu solo están donde las imaginamos (...) Aunque las tangibles, esas sí, nos tocan la piel y hasta nos la perforan si las transgredimos".

The Bottle no es un ser vivo, pero sí es un objeto que viaja sin ser detenido por un oficial de aduanas, su rumbo es incierto y su presencia de plástico es contestataria: la boya transgrede las líneas imaginarias, va libre por la mar sin ejercer violencia, solo flota y la marea la lleva. "La boya de la incertidumbre fue lanzada, como un acto de la conciencia que sabe que la humanidad ha perdido su brújula y que, a tientas, sigue avanzando, en la taquicardia colectiva que secretamente implora que la niebla se disipe y nos conceda un respiro: el privilegio de la esperanza y de la paz" (Grobet, 2007) [Figura 5].

\section{LA FRONTERA FOTOGRÁFICA, EL REGISTRO CARTOGRÁFICO Y EL REGISTRO FOTOGRÁFICO}

Para trazar un mapa hay que observar. El resultado de esta observación se materializa en un objeto que, como bien señala la especialista en cartografía medieval, María Luisa Durán y Casahonda Torack (2016), es un instrumento de poder, una construcción social donde se "reflejan los motivos políticos, o personales, de quienes los elaboran y de quienes los consumen”. Observar y registrar con una cámara también tienen, como la serie de acciones que requiere el registro cartográfico, implicaciones de poder. No cualquiera tiene una cámara, los materiales de las que está hecha, como el plástico, los minerales de la batería y los metales conllevan complejos procesos industriales y de explotación de la tierra. En la fotografía existe alguien que decide que puede fotografiar a los otros, los fotografiables. ¿Cómo se sienten esos otros al ser objetos de la mirada de alguien más, contando o no con su consentimiento?

En este caso Lourdes Grobet, en el Ártico, toma fotografías y videos de forma consensuada, llega a Alaska porque decidió que algo o alguien son retratables. Con ello surgen preguntas: ¿Qué implica la presencia de una mujer blanca -si bien es latinoamericana, su fenotipo es de alguien "blanco" - vaya a una comunidad indígena a más de ocho mil kilómetros de distancia de su casa para observar desde su lente?

La cámara en ese aspecto remite a su vez a los mapas. Este invento es un instrumento que de igual modo es agresivo y que ha servido para controlar: como las fotografías de prostitutas en el Registro de mujeres públicas creado en 1865 durante el gobierno de Maximiliano en Ciudad de México, las fotografías que dan cuenta de la entrada de personas a una cárcel, las cámaras de seguridad o la fotografía de un pasaporte que da fe de la identidad de quien intenta cruzar una frontera. Bien señala Sontag que a partir "del uso que les dio la policía de París en la sanguinaria redada de los communards en junio de 1871, los Estados modernos emplearon las fotografías como un instrumento útil para la vigilancia y control de poblaciones cada vez más inquietas. En otra versión de su utilidad, el registro de la cámara justifica” (2013, pp. 15-16).

Fotografiar, al igual que mapear, es un acto de poseer. Hay algo que es depredador en la acción de tomar una fotografía, que, como lo explica Sontag, "transforma a las personas en objetos que pueden ser poseídos simbólicamente” (p. 24). Una fotografía representa un espacio y, también, tiene un límite. Quien captura decide hasta dónde va a ver el espectador, marca otro tipo de fronteras en el mundo de la visualidad. Quien fotografía elige y a su vez discrimina entre lo que merece ser retratado y lo que no.

Lourdes Grobet es consciente de ello. Si bien ejerce una posición de poder al aprehender al fotografiado, tras más de cinco décadas de trayectoria, es reconocida por su interés por colaborar en equipo, en proyectos que involucran varios años 
de trabajo, y por la intimidad que consigue reflejar en sus retratos. Ante la pregunta sobre la relación con quienes aparecen en la pantalla, responde: "Mi táctica de trabajo es que cuando llego a filmar o a trabajar a algún lugar que no conozco, no saco equipo de ningún tipo hasta que no se establece la relación de amistad con la gente". De este modo, poco a poco gana la confianza de los pobladores, tanto ella como el resto del grupo de mexicanos en Beringia. "Mi equipo de filmación jugaba y hacía deporte con los chavos del lugar (...), y así, les explicamos que haríamos un documental, describiendo su situación social y política (...) La respuesta fue muy buena. Me siento muy contenta", explica Grobet durante entrevista.

Esta forma de trabajo en que se prioriza la relación respetuosa se manifiesta en sus trabajos anteriores como en sus series sobre lucha libre en los que, tras años de amistad y cercanía con los y las luchadoras, Grobet consigue fotografías íntimas. Prueba de esta cercanía se observa en sus libros Espectacular de lucha libre (2008) o Retratos de familia (2009).

Por su trayectoria profesional, se puede suponer que Grobet sabe trabajar en equipo, como en grupos de artistas; de hecho, mucho del material fotográfico que existe de las piezas efímeras del grupo Proceso Pentágono fue tomado por ella. Su capacidad y disposición para el trabajo colaborativo cobra gran importancia en este contexto: la artista llega y se implica con la comunidad, paulatinamente gana la confianza de los habitantes y se vuelve cercana, como se puede ver en escenas tan privadas como el interior de una casa o en una escuela. Llega a un rincón de una sala porque le dan ese permiso, el de registrar algo tan privado que se vuelve público para los observadores que son radicalmente lejanos a la realidad de

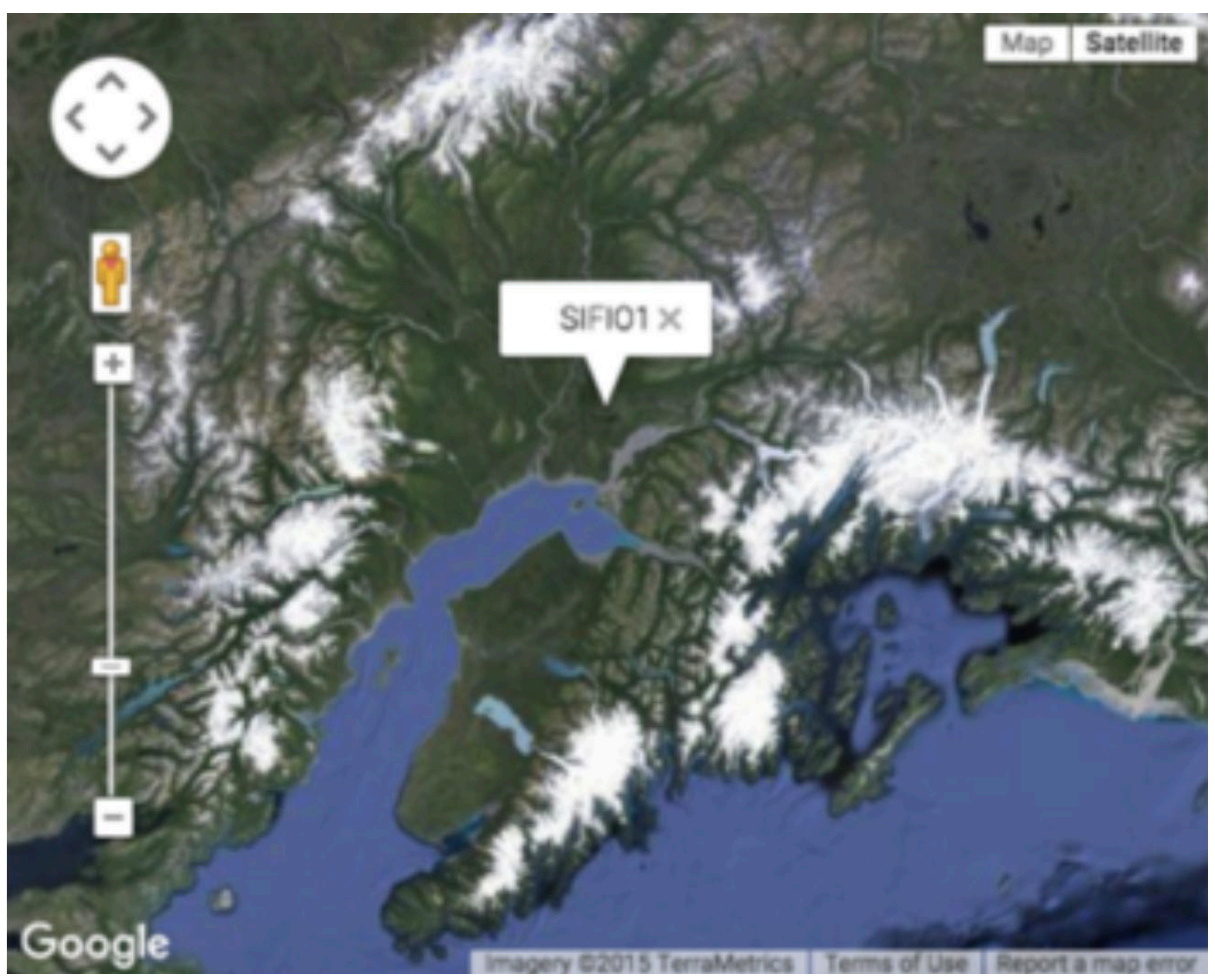

FIGURA 5.

Captura de pantalla con la ubicación de The Bottle en otoño de 2016. 
este pueblo de Alaska. En el momento en que se exhibe en la sala de cine, el público se apropia, en su medida, de lo que miró Lourdes Grobet.

En cuanto a las formas de relacionarse con su equipo tiene lineamientos éticos claros que también son posturas políticas: "Creo en el trabajo horizontal. Pedí a cada uno de los miembros del equipo que ellos propusieran y llevaran a cabo alternativas desde la profesión de cada uno. Creo que se logró un buen trabajo".

Respecto a la convivencia con los habitantes de la Diómedes Menor, la directora explica en entrevista que todo "fue muy cordial”, ya que "cuando a la gente la tratas bien, tienes buena respuesta”. Es notoria la proximidad: los niños voltean a la cámara, una mujer cuenta sobre cómo conoció a su esposo, otra habla del luto y la maternidad, una profesora platica sobre su docencia y también los salones de clases aparecen en el filme. Las mejillas rojas de los niños contrastan con los distintos tonos de azul y blanco del paisaje; y los colores cálidos de las habitaciones, esos espacios tan íntimos, desentonan con la frialdad del exterior y sus paisajes árticos: mar, montaña y cielos de colores gélidos. Es también en el paisaje donde confluye la cartografía y la fotografía.

Ante la pregunta sobre la vida cotidiana de las personas que conoció y retrató, la artista explica: "Lo que más me sorprendió fue que iba a visitar a la etnia más antigua de la humanidad y los encontré instalados en la modernidad. Conservando, a la vez, todavía, modos de vida sustentable”. Es la suma de distintos tiempos y realidades, con distintas formas de consumir. Son parte de Estados Unidos en el siglo XXI y hacen compras por internet, pero también provienen de una estirpe de cazadores: matan aves, osos, focas y ballenas, comen su carne y utilizan su piel como vestido. Es una caza moderada, consumen lo que necesitan y lo hacen con cuidado: "En silencio (...) Hay respeto por el animal”, como explican los cazadores en el documental [Figura 6].

\section{Conclusiones}

El uso de la fotografía y la discusión sobre la construcción de las fronteras es uno que se trata en Bering. Equilibrio y resistencia, ya sea por la misma fotografía cinematográfica, como por el trabajo de Grobet como fotógrafa, o por el papel que tiene la fotografía para los habitantes en el momento de contar sus historias. Si bien el documental es sobre la región de Beringia, este fue hecho por una artista mexicana que conoce las problemáticas de la migración y que, desde su quehacer artístico, cuestiona la arbitrariedad de las divisiones nacionales y la construcción de los Estados.

Sus preocupaciones respecto a la migración y la instauración de las fronteras son parte indispensable de su trabajo desde hace décadas. Grobet articula su quehacer artístico plástico con su quehacer cinematográfico. En ese sentido, al trabajar de forma interdisciplinaria, borra otro tipo de fronteras.

Los mapas, como registro de los territorios, son, al igual que la fotografía y la cinematografía, herramientas y modos de ejercer un poder sobre los cuerpos y territorios. Hay una relación entre observar, representar y conquistar; entre mapear y fotografiar. Las consecuencias de la arbitraria división del siglo XIX de la región de Beringia son observadas por Lourdes Grobet de una forma única en nuestros días. La artista logró una cercanía inigualable con los habitantes en Alaska. Se sentó a la mesa con una cultura con tradiciones distintas a la suya, pero que coinciden con el ser parte de las sociedades, como explica Segato, del "nuevo mundo", en que las bases de modos de conquista fueron sentadas por los Estados metropolitanos, y ahora son controlados por elites blancas.

La postura de la artista es crítica ante la violencia que ha significado la separación de la región de Beringia. A lo largo del documental se cuestionan las fronteras, pero del mismo modo no deja de existir una línea divisoria entre el lente, la edición y la dirección que narran y presentan. No es posible una conciliación entre quienes observamos con quienes son observados, fotografiados o mapeados. 
En el filme se observa el establecimiento de un diálogo con pobladores de Alaska del que la cámara es testigo: ella como directora es la que consigue el permiso para entrar, luego va su cámara. Grobet trabaja en equipo, y del mismo modo forma equipo con los habitantes de Alaska: heredera de las formas de hacer política dentro del espacio de lo personal y de lo cotidiano de la década de los 70 en México, se acerca y aprende al ritmo que le es permitida. Al igual que en otros de sus proyectos artísticos, hace cine y documental al seguir los procesos de trabajo que ha utilizado por años para hacer fotografía e instalación, en que da profunda importancia al trabajo de campo y al prolongado sobre los proyectos cortos.

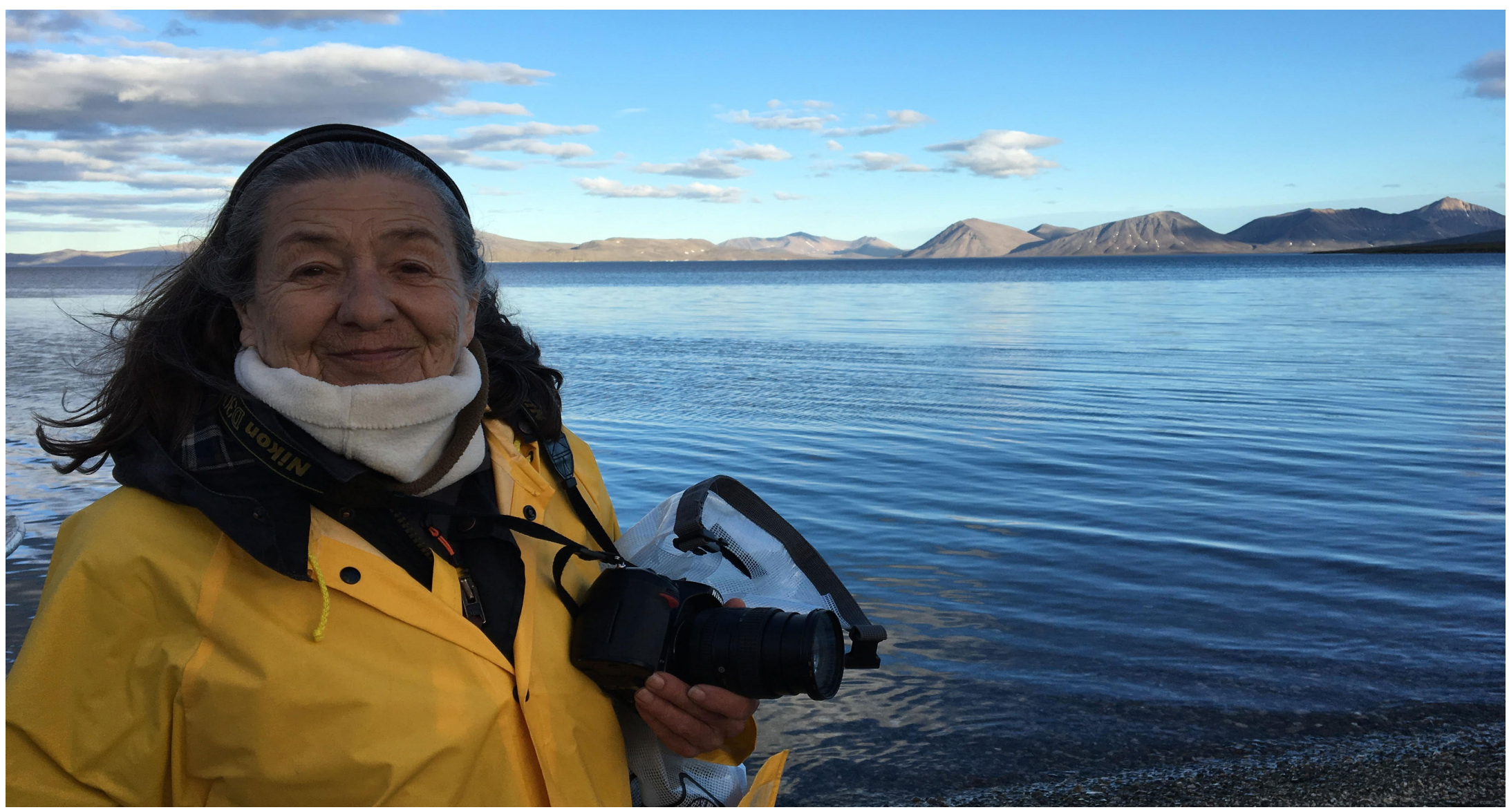


Anderson, B. (1993). Comunidades imaginadas. Reflexiones sobre el origen y la difusión del nacionalismo. Ciudad de México: México: Fondo de Cultura Económica.

Banco De México. (2018). Ingresos por remesas [Archivo de datos]. Recuperado de http://www.banxico.org.mx/SieInternet/consultarDirectorioInternetAction. do? sector $=1 \&$ accion $=$ consultarCuadro\&idCuadro $=$ CE $81 \&$ locale $=$ es

Durán y Casahonda Torack, M. L. (2014). Cartografía cosmológica medieval. Platonismos y neoplatonismos: un constructo ideológico (Tesis de Doctorado). Universidad Iberoamericana, México.

Durán y Casahonda Torack, M. L. (2016). Deconstrucción y construcción cartográfica: nuevas miradas y lecturas. Conferencia presentada en Coloquio de Cultura Visual, Oaxaca, México [Archivo de audio]. Recuperado de https://culturasvisuales.org/2016/10/09/mesa-relacion-entre-cultura-visual-y-creacion-artistica

García, P. (2015). Expediente Grupo Proceso Pentágono. En Grupo Proceso Pentágono. Políticas de la intervención 1969-1975-2015 (pp. 21-42). Ciudad de México, México: MuAC.

Goldman, S. M. (1982). Six Women Artist of Mexico. Woman's Art Journal, 3(2), 1-9. doi: https://doi.org/10.2307/1358027

Grobet, L. (2007). The Bottle. Recuperado de http://thebottle.com.mx/

Kurki, T. y Laurén, K. (2012). Borders and Borderlands. Interview with Associate Professor Stephen Wolfe. Folklore, (52). doi: https:/doi.org/10.7592/ FEJF2012.52.interview_kurki_lauren

Muñoz, V. (2018, marzo). Lourdes Grobet. Photography and Environment. Recuperado de https://lourdesgrobet.com/en/biography/

Raqs Media Collective. (2009). Machines Made to Measure: On the Technology of Identity and the Manufacture of Difference. En C. Nold (Ed.), Emotional Cartography. Technologies of the Self (pp. 15-26). Recuperado de http://emotionalcartography.net

Roseluo, M. y Wolfe, S. F. (2017). Introduction. En J. Schimanski y S. F. Wolfe (Eds.), Border Aesthetics. Concepts and Intersections (pp. 1-25). Nueva York, EE.UU.: Berghahn.

Segato, L. R. (2007). El color de la cárcel en América Latina. Apuntes sobre la colonialidad de la justicia en un continente en desconstrucción. Nueva sociedad, (208), 142-161. Recuperado de http://nuso.org/articulo/ apuntes-sobre-la-colonialidad-de-la-justicia-en-un-continente-en-desconstruccion/ 
Sontag, S. (2013). Sobre la fotografía. Ciudad de México, México: Random House.

Department of Treasury. (1868). Treasury Warrant in the Amount of $\$ 7.2$ Million for the Purchase of Alaska. Washington, EE.UU.: National Archives Catalog. Recuperado de https://catalog.archives.gov/id/301667

\section{Filmografía}

Grobet, L. (Directora) \& Ruiz Ruiz-Funes, R. (Productor). (2013). Bering. Equilibrio y resistencia. México: Catatonia Cine.

Eréndira Derbez Campos (México) estudió Historia del Arte en la Universidad Iberoamericana (Ciudad de México). Actualmente cursa la Maestría en Estudios de Arte de dicha universidad y es Asistente para el Fortalecimiento de la Calidad Académica del Departamento de Arte (AFCA) de la misma. Está próxima a publicar, en colaboración con Claudia de la Garza, el libro No son micro, machismos cotidianos (2020), y el artículo "Bordados por la paz, protesta silenciosas, archivo de puntadas", con Rodrigo Illescas, en H-ART. Revista de historia, teoría y crítica de arte, de la Universidad de los Andes. 